\title{
ANE - Jogos Educativos para Auxiliar Crianças com Deficiência Intelectual no Aprendizado do Alfabeto, Numerais e Emoções
}

\author{
Juliana F. Bentes ${ }^{1}$, Fabiola P. Oliveira ${ }^{2}$, Yomara Pinheiro Pires ${ }^{1}$ \\ ${ }^{1}$ Faculdade de computação (FACOMP) - Universidade Federal do Pará (UFPA) \\ 68746-360 - Castanhal - PA - Brasil \\ 2 Instituto de Ciências Exatas e Naturais (ICEN) - Universidade Federal do Pará (UFPA) \\ 66075-110 - Belém - PA - Brasil \\ \{juliana.fbentes@gmail.com, fpoliveira@ufpa.br, yomara@ufpa.br\}
}

\begin{abstract}
Resumo. Este trabalho propõe facilitar a alfabetização, reconhecimento dos numerais $e$ das emoções humanas em crianças com Deficiência Intelectual, através de um aplicativo de jogos lúdicos adaptados às necessidades e dificuldades do público-alvo. Para a realização deste projeto foram coletados dados relativos ao Atendimento Educacional Especializado prestado no município de Castanhal, no intuito de levantar os requisitos do sistema e identificar potenciais usuários da ferramenta desenvolvida. Após a realização de testes junto aos usuários finais, obtiveram-se dados suficientes que amparam a justificativa e motivação do projeto desenvolvido, assim como também atingiram-se resultados satisfatórios ao alcançar os objetivos previamente definidos com 100\% dos usuários afirmando que o aplicativo é uma boa ferramenta de auxílio para responsáveis e profissionais de educação especial no desenvolvimento cognitivo de crianças e adolescentes portadores de Deficiência Intelectual.
\end{abstract}

\begin{abstract}
This work aims to facilitate literacy, the recognition of numerals and human emotions in children with Intellectual Disabilities, through the application of playful games adapted to the needs and difficulties of the public. In order to carry out this project, data were collected regarding the Specialized Educational Service provided by the municipality of Castanhal, in order to raise the requirements of the identify potential users of developed hardware. In order to carry out the tests with the end users, sufficient data were obtained to support the justification and motivation of the developed project, in addition to obtaining satisfactory results to achieve the previously defined objectives, with $100 \%$ of users stating that the application is a good tool for assistance for responsibility and special education professionals, in children's cognitive development with Intellectual Disability.
\end{abstract}

\section{Introdução}

A Deficiência Intelectual é tida como uma das mais comuns deficiências encontradas em crianças e adolescentes, atingindo cerca de $1 \%$ da população jovem [VANCONCELOS, 2004]. Possui como principal característica a redução no desenvolvimento cognitivo normalmente abaixo do esperado para a idade da criança ou adulto, acarretando muitas vezes um desenvolvimento mais lento na fala, no desenvolvimento neuropsicomotor e em outras habilidades. Tendo isso em vista, a área de Tecnologia Assistiva tem ganhado cada vez mais destaque uma vez que tem o potencial de proporcionar uma significativa melhoria na qualidade de vida das pessoas com deficiência, tornando-se uma ferramenta indispensável a ser inserida no processo de ensino-aprendizagem e avaliação da criança com deficiência 
intelectual, uma vez que a mesma já está em constante contato com recursos tecnológicos, seja em casa ou até mesmo no ambiente escolar, que podem ser usados para impulsionar seu desenvolvimento cognitivo e até mesmo para auxiliar no seu tratamento [BERSH, 2017].

Diante do que fora apresentado, este projeto propõe a criação de um aplicativo que auxilie nos processos educacional e avaliativo da criança com Deficiência Intelectual, utilizando-se de jogos educativos visando auxiliar no aprendizado do infante deficiente intelectual - inicialmente do Alfabeto, Numerais e Emoções (ANE) - facilitando assim a avaliação didático-pedagógica realizado por profissionais do ensino no Atendimento Educacional Especializado de crianças com grau de Deficiência Intelectual moderado do ensino infantil. O aspecto lúdico do aplicativo se insere como fator motivacional diante da Teoria da Aprendizagem segundo Jean William Fritz Piaget, que subdividiu o desenvolvimento cognitivo da criança em quatro fases, das quais em duas delas, a ludicidade deve ser inserida como recurso educacional, a saber, nas fases Pré-Operacional (dos 3 aos 7 anos) e na fase Operatório Concreto (dos 8 aos 11 anos) [MOREIRA, 1999].

Este artigo está dividido da seguinte forma: a sessão 2 apresenta trabalhos correlatos e uma comparação com o aplicativo ANE. A sessão 3 menciona a metodologia aplicada ao trabalho. A sessão 4 explora as ferramentas utilizadas no desenvolvimento do aplicativo ANE, bem como os recursos do sistema. Na sessão 5 são apresentados os resultados obtidos com o sistema a partir de testes realizados junto aos usuários finais. A sessão 6 apresenta as considerações finais e trabalhos futuros.

\section{Trabalhos Correlatos}

Na última década foram desenvolvidos diversos softwares voltados ao público autista tendo como proposta central uma intervenção educacional. Por possuírem uma abordagem similar a este projeto, dois deles serão apresentados a seguir, assim como também um comparativo entre as tecnologias mencionadas e o aplicativo ANE.

O aplicativo TEO (Tratar, Estimular e Orientar) ${ }^{1}$, trata-se de um ambiente de jogos lúdicos interativos divididos em seis categorias - associação, RLM (Raciocínio Lógico Matemático), quebra-cabeça, memória, atividades de vida diária e localização. Possui foco no atendimento de crianças com Transtorno do Espectro Autista (TEA), tendo como objetivo garantir uma abordagem multidisciplinar a fim de que a criança com TEA alcance seu potencial máximo [MOURA 2016]. Outro software a se mencionar é o ACA (Aprendendo com Comunicação Alternativa), trata-se de um aplicativo voltado ao ganho de vocabulário e auxílio à alfabetização do indivíduo autista utilizando design de tela multi-toque [GOBBO et al. 2019].

Embora tenha o público autista como alvo, o software TEO não possui aplicação voltada à alfabetização, ensino de numerais ou emoções, como se propõe o aplicativo ANE. Apesar de ter utilizado a mesma plataforma empregada no desenvolvimento do aplicativo ANE (Construct 2.0), o aplicativo ACA não utiliza de recursos drag-and-drop ("arrastar-esoltar", em tradução livre) nas atividades propostas, embora seja muito útil para estimular o

\footnotetext{
${ }^{1}$ https://github.com/thiagobrunoms/TEO
} 
desenvolvimento motor da criança. Outro ponto negativo a ser destacado em ambas as aplicações mencionadas é o exclusivo interesse em trabalhar as deficiências específicas de crianças autistas, ignorando demais deficiências e/ou limitações de ordem intelectual, ao contrário do aplicativo ANE, que não se limita àqueles que se enquadram no espectro do autismo, podendo ser aplicado também a usuários portadores de outras deficiências de ordem intelectual, como atrasos no desenvolvimento, Transtorno do Déficit de Atenção com Hiperatividade (TDAH), entre outros.

\section{Metodologia}

Para o levantamento dos requisitos dos jogos, inicialmente foi realizada uma pesquisa bibliográfica em portais de revistas científicas e em repositórios institucionais a fim de obter informações sobre trabalhos correlatos e a aplicabilidade prática de softwares semelhantes no meio acadêmico. A Deficiência Intelectual também foi alvo de pesquisa literária, a fim de adquirir uma compreensão melhor de todo o espectro que envolve os tipos de DI. Com base nos dados obtidos foi possível definir os softwares necessários à execução do projeto e traçar os objetivos geral e específicos.

Numa primeira visita à Secretaria Municipal de Educação (SEMED) da cidade que sediou a pesquisa, foi realizada uma entrevista não estruturada dirigira à assessora técnica responsável pelo setor de educação inclusiva para a obtenção de informações gerais sobre o funcionamento do atendimento educacional especializado prestado nas escolas regionais. Deu-se então início à segunda parte das entrevistas no setor de educação inclusiva, agora na modalidade estruturada ao ser encaminhado um ofício contendo o questionário pontual sobre dados e informações do atendimento educacional especializado prestado no município. Com base nas informações e dados obtidos com as entrevistas não estruturada e estruturada na SEMED, foi possível o levantamento de parte dos requisitos funcionais e não funcionais que o sistema deveria possuir. Para o levantamento dos requisitos do sistema e validação de cada etapa de desenvolvimento do projeto foi consultada uma profissional da área de educação especial inclusiva infantil que presta atendimento educacional especializado como mediadora de alunos deficientes intelectuais na rede de escolas municipais.

\section{O Aplicativo ANE}

Para o desenvolvimento dos jogos ANE (Alfabeto, Numerais e Emoções) foi utilizado o software Construct $2^{2}$, um criador de jogos em HTML5 projetado especialmente para jogos em duas dimensões desenvolvido pela Scirra ${ }^{3}$. Para uma melhor navegabilidade, foi preparado um menu principal, onde o usuário poderá escolher o jogo do seu interesse, tendo três opções: Jogo do Alfabeto, Números e Emoções. Na tela do menu inicial também encontra-se um ícone na extremidade inferior direita, que direciona o usuário para uma tela com informações sobre o jogo, conforme ilustrado na Figura 1.

\footnotetext{
${ }^{2}$ https://www.scirra.com/construct2

${ }^{3}$ https://www.scirra.com/
} 


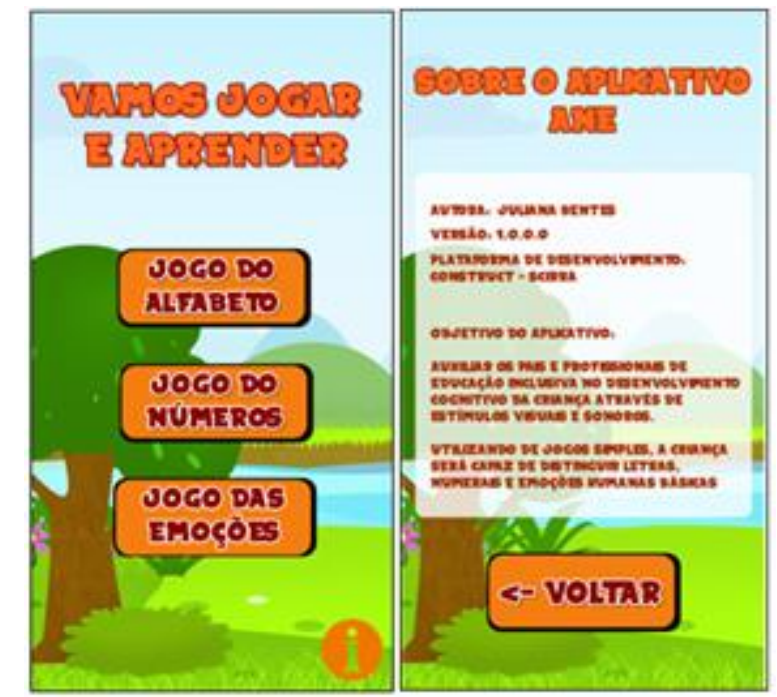

Figura 1 - Menu Principal e Informações Sobre o Aplicativo

Fonte: Autoria Própria (2019)

Segundo a Teoria da Aprendizagem de Piaget, durante a $2^{\mathrm{a}}$ fase do desenvolvimento cognitivo da criança, conhecida como fase Pré-Operatória (que vai dos 3 aos 7 anos), seu pensamento funciona por analogia, estabelecendo relações comparativas entre dados [MOREIRA, 1999]. Nos jogos do Alfabeto, Numerais e Emoções o usuário aprenderá as letras, números e as quatro emoções (alegria, raiva, medo e tristeza) através de estímulos sonoros e visuais, sendo-lhe apresentados em conjunto com objetos e animais para associação, facilitando o aprendizado segundo as características da fase Pré-Operatória.

As telas de apresentação inicial das letras possuem um fundo branco e a letra maiúscula em destaque, tendo logo abaixo a descrição textual em maiúsculo e letra bastão cursiva do objeto ou animal para associação, assim como também uma imagem para facilitar a memorização (Figura 2). Ainda segundo a Teoria de Aprendizagem de Piaget, durante a $3^{\mathrm{a}}$ fase de desenvolvimento cognitivo, denominada Operatório Concreto (dos 8 aos 11 anos), a criança atinge o uso das operações completamente lógicas com base em proposições e enunciados [MOREIRA, 1999]. Todos os jogos educativos ANE contêm telas onde o usuário deverá escolher a opção correta entre duas, estimulando assim a sua capacidade de tomar decisões lógicas com base nas proposições a associações apresentadas nas telas anteriores (Figura 3). Por exemplo, a primeira fase do jogo do Alfabeto, que vai da letra "A" até a letra " $\mathrm{D}$ ”, possui um total de doze telas dinâmicas que reúnem os recursos de associação e arrastare-soltar. Para o desenvolvimento dos jogos, foi consultada uma profissional da área de educação inclusiva que validou cada etapa do desenvolvimento. 


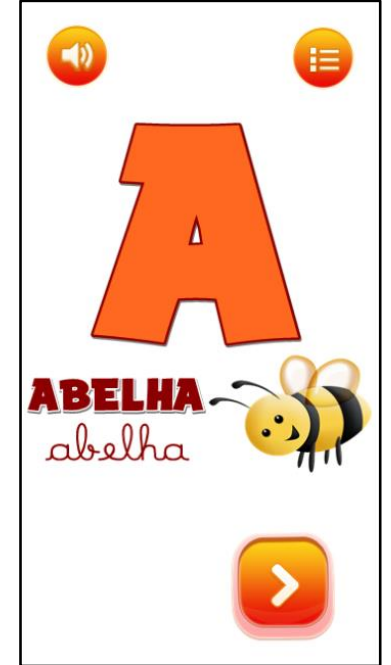

Figura 2 - Apresentação Inicial da Letra A (Jogo do Alfabeto)

Fonte: Autoria própria (2019)

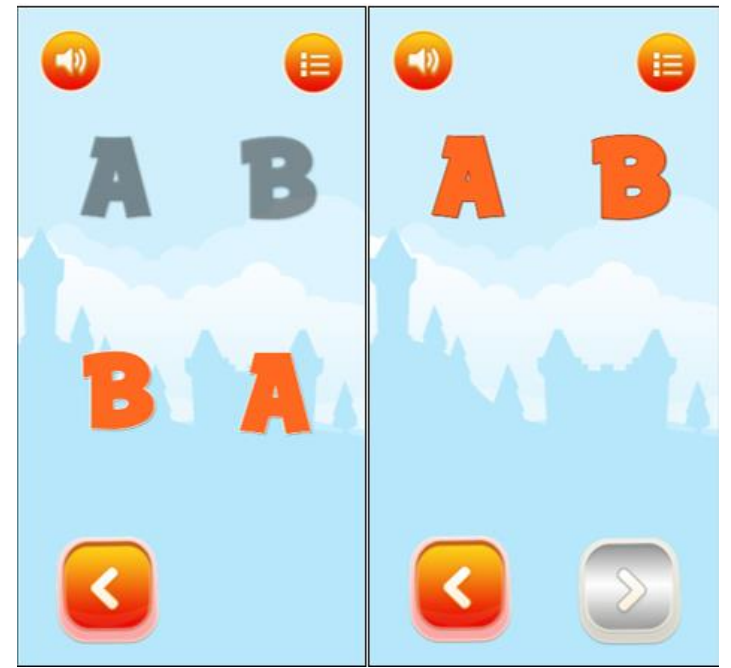

Figura 3 - Distinção das letras utilizando o arrastar-e-soltar (Jogo do Alfabeto)

Fonte: Autoria própria (2019)

O objetivo da aplicação do recurso de arrastar-e-soltar é trabalhar a coordenação motora do usuário, que é frequentemente limitada e subdesenvolvida em pessoas portadoras de algum tipo de Deficiência Intelectual. A qualquer momento o usuário poderá ouvir novamente a instrução ou repetir a mesma atividade, clicando no botão de áudio na extremidade superior esquerda. O usuário também poderá facilmente retornar ao menu inicial selecionando o botão de menu, localizado na extremidade superior direita da tela, que oferece ao usuário as opções de voltar ao jogo ou regressar ao menu inicial.

Outro tipo de atividade que se encontra no jogo do Alfabeto é a possibilidade de o jogador escolher dentre duas opções a que corretamente se adequa ao questionamento levantado. Por exemplo, o usuário é incentivado, através de estímulos visuais - e sonoros a escolher entre duas opções de letras apresentadas a que corretamente se aplica ao objeto apresentado. O mesmo padrão se repete nas demais fases do jogo do Alfabeto, assim como também dos Numerais e Emoções, conforme demonstrado nas Figuras 4, 5 e 6.

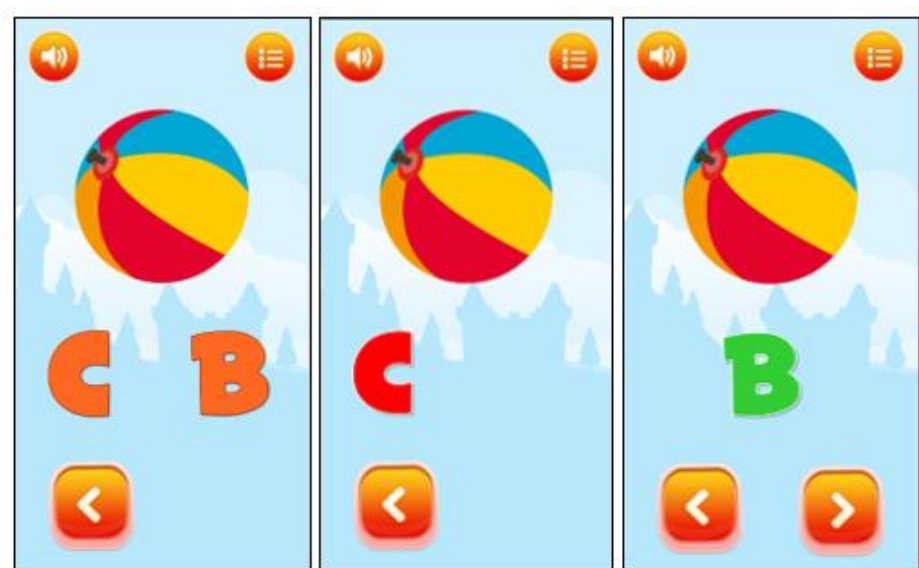

Figura 4 - Escolha a Letra Correta

(Jogo do Alfabeto)

Fonte: Autoria própria (2019) 


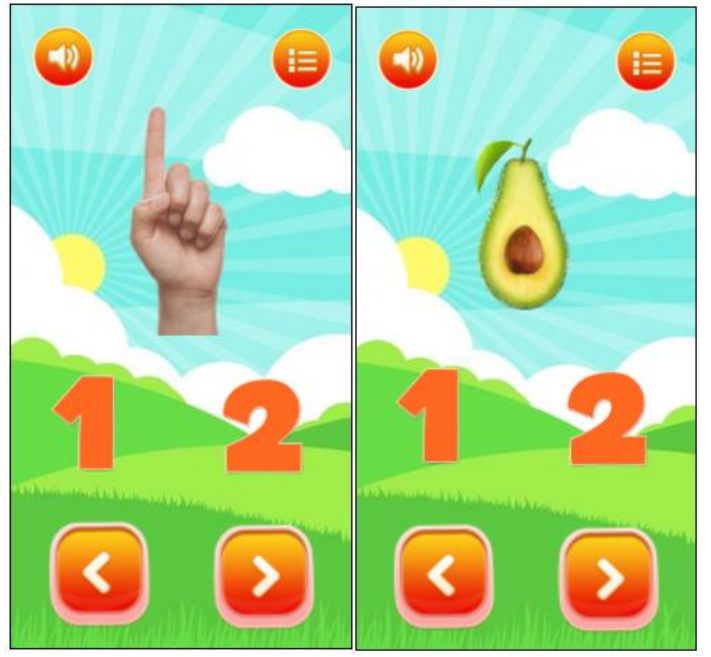

Figura 5 - Escolha o Número Correto (Jogo dos Números)

Fonte: Autoria própria (2019)

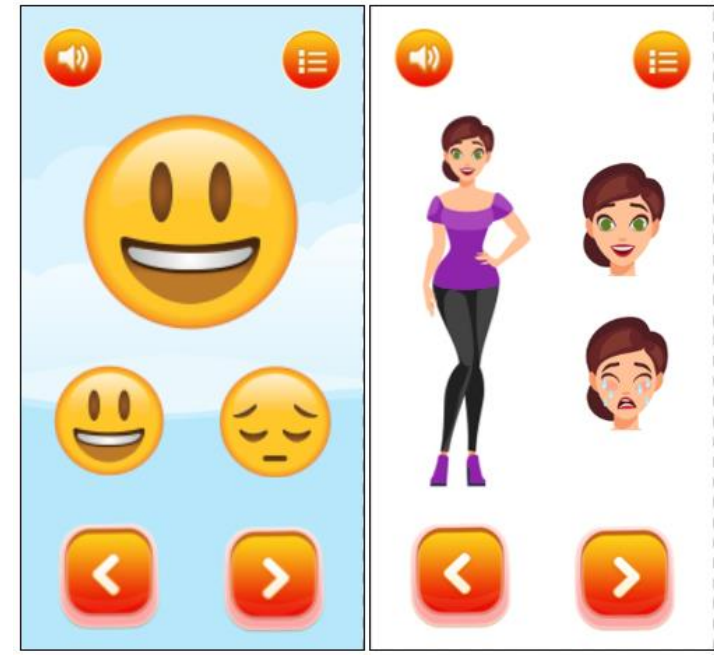

Figura 6 - Escolha a Emoção Correta (Jogo das Emoções)

Fonte: Autoria própria (2019)

Ao selecionar a letra, número ou emoção errada, o usuário é repreendido com um efeito sonoro e é incentivado a tentar mais uma vez, quando então aparecem novamente as duas opções. Ao selecionar a opção correta, o jogador é parabenizado podendo passar para a próxima tela conforme indicado pela seta na extremidade inferior direita. A mesma lógica sequencial pode ser observada nos demais jogos contidos no aplicativo.

\section{Testes e análise dos resultados obtidos}

Os testes foram realizados com alunos da escola municipal de ensino infantil e fundamental (EMEIF) Luís Augusto Paiva de Oliveira da rede municipal de ensino de Castanhal - PA. Por possuir uma sala equipada para o atendimento educacional especializado, esta escola atende à demanda regional com um grande número de alunos portadores de deficiência de variados tipos e em diferentes graus. Dentre eles, incluem-se crianças com Deficiência Intelectual cursando o ensino fundamental menor (de primeira à quarta série), público-alvo deste projeto, os quais participaram na realização dos testes sob a supervisão de responsáveis e professores mediadores de educação inclusiva.

Para obter as autorizações dos responsáveis através da assinatura do Termo de Consentimento Livre e Esclarecido, foi inicialmente solicitado junto à Secretaria Municipal de Educação (SEMED) a listagem de escolas que prestam atendimento educacional especializado. A direção da escola, em conjunto com a coordenação de atendimento educacional especializado, atuou na seleção das crianças com o perfil adequado à realização dos testes, bem como na coleta da autorização dos responsáveis das mesmas.

\subsection{Questionário Pré-teste}

Antes da realização dos testes, os mediadores e/ou responsáveis presentes preencheram um questionário inicial pré-teste no qual eram solicitadas informações sobre o(s) tipo(s) de Deficiência Intelectual da criança, idade, acesso a smatphones e/ou tecnologias similares, 
além da relevância da utilização de aplicativos como recurso educacional do ponto de vista do profissional de educação inclusiva e/ou responsável.

A partir da análise dos dados coletados através do preenchimento do questionário pré-teste, pode-se abstrair que participaram dos testes um total de 10 (dez) alunos portadores de diferentes tipos de Deficiência Intelectual, sendo que o espectro do autismo se destaca entre a amostra de alunos selecionados. Isso se deve ao fato de que alguns dos alunos apresentava características comuns ao espectro do autismo em conjunto ou cumulativamente a outro tipo de Deficiência Intelectual qualquer. Quanto ao acesso à dispositivos tecnológicos, concluímos que a maioria dos alunos possuem acesso à smatphones, computadores de mesa ou tablet.

As idades dos participantes vão de 4 a 14 anos, todos de turmas do ensino fundamental menor (de $1^{\circ}$ a $4^{\circ}$ anos do ensino fundamental de nove anos). Quanto à relevância na utilização de aplicativos como recurso educacional, a grande maioria (90\%) dos responsáveis e professores de alunos portadores de Deficiência Intelectual julgou como sendo "Muito Relevante" como recurso extra nas práticas didático-pedagógicas. Os demais (10\%) julgaram-se "Indiferentes" à utilização de aplicativos lúdicos como recurso pedagógico.

Os dados da pesquisa demonstraram que menos da metade (40\%) dos responsáveis e/ou profissionais de educação inclusiva entrevistados já haviam utilizado aplicativos lúdicos como método de ensino-aprendizagem junto às crianças portadoras de Defíciência Intelectual, dando preferência aos métodos didáticos mais tradicionais.

\subsection{Teste com os Usuários Finais}

Inicialmente o aplicativo fora apresentado aos pais e professores, sendo explicados os objetivos de cada jogo. Após a apreciação do aplicativo pelos professores e responsáveis presentes, os alunos foram submetidos à utilização dos jogos na sala de Atendimento Educacional Especializado (AEE) da escola selecionada, sob a supervisão dos professores, coordenadora de AEE e alguns responsáveis. Os responsáveis e/ou professores presentes foram orientados a prestar atenção quanto ao comportamento do aluno logo antes do início da realização das atividades propostas nos jogos, e a receptividade do mesmo em utilizar o smartphone e o jogo em si.

Cada aluno podia levar o tempo que fosse necessário para a conclusão dos jogos, os professores e/ou responsáveis somente interviam quando o aluno pedia ajuda ou tivesse clara dificuldade em passar nas fases dos jogos. A presença e atenção dos professores e responsáveis foi essencial para a coleta de resultados que será apresentada no próximo tópico, pois os alunos não possuíam as habilidades necessárias para o preenchimento dos formulários de avaliação do jogo, devido às limitações impostas pela Deficiência Intelectual.

Após a realização dos testes pelos alunos sob a supervisão dos mediadores e/ou responsáveis, estes últimos foram convidados a preencher o questionário pós-teste, constando um total de dezessete enunciados que dissertam sobre a facilidade em usar o aplicativo, comportamento da criança durante o período de testes, aspectos técnicos (cores da interface, qualidade dos efeitos sonoros, duração das fases, etc) e relevância do aplicativo nas práticas pedagógicas, bem como as correspondentes respostas na escala de Likert (Discordo 
Totalmente, Discordo, Neutro, Concordo, Concordo Totalmente) para facilitar a computação e agrupamento das respostas de maneira padronizada. Neste questionário também foram solicitadas sugestões de melhoria, além de uma avaliação geral de usabilidade dos jogos. Como exemplo, alguns dos enunciados presentes no questionário: A criança se mostrou receptiva a utilização do aplicativo; Foi fácil para a criança aprender a usar este aplicativo; A organização dos menus e comandos de ação é lógica, permitindo encontrá-los facilmente na tela; As cores utilizadas no aplicativo são agradáveis e as imagens de boa qualidade; Os efeitos sonoros funcionam de maneira satisfatória; Achei apropriada a duração de cada fase; A criança manteve o interesse nas atividades do aplicativo durante o período de testes; $\mathrm{O}$ aplicativo realiza satisfatoriamente aquilo a que se propõe; Eu recomendaria este aplicativo para outras pessoas, entre outras perguntas.

\subsection{Análise dos Resultados Obtidos}

Com base nos dados obtidos a partir do questionário pós-teste preenchido pelos professores e responsáveis presentes, pôde-se observar que houve uma boa receptividade por parte de todos os alunos participantes. De acordo com o que os professores e responsáveis puderam observar, a maioria $(80 \%)$ dos alunos participantes da pesquisa tiveram grande facilidade em aprender as regras do jogo e a utilização do aplicativo como um todo. Pode-se afirmar ainda, que a navegabilidade foi facilitada em parte pela padronização na distribuição de elementos nas telas, no intuito de não causar estranhamento ao aluno e possibilitar a memorização da localização dos elementos principais que compõem as telas.

A grande similaridade da interface do aplicativo com outros do gênero desenvolvidos para as plataformas Android e $\mathrm{iOS}^{4}$ também contribuiu para uma maior fluidez nas trocas de telas e menus dentro do aplicativo. Como consequência dessa similaridade, os responsáveis e/ou professores presentes não foram surpreendidos pelo comportamento geral do aplicativo.

Outra característica elogiada foi a facilidade na leitura dos textos presentes nas telas do aplicativo. Os dois tipos de escrita escolhidos para os textos do aplicativo, bastão e cursiva, são os mais frequentemente utilizados no processo de alfabetização em sala de aula, o que não causa estranhamento no aluno, pois o mesmo já está familiarizado com esses dois tipos de escrita. As cores que se destacam na composição do aplicativo também não foram escolhidas a esmo. Segundo pesquisas baseadas em cromoterapia, as cores laranja e amarela servem de estímulo à socialização e criatividade da criança, enquanto que a cor azul estimula um sentimento de calma, reduzindo a ansiedade e induzindo a um estado de relaxamento [SILVA, 2013].

Um aspecto do aplicativo que dividiu opiniões foram os efeitos sonoros, considerados insatisfatórios para $30 \%$ dos entrevistados devido à ocorrência de certos comandos repetitivos que se tornaram incômodos em determinado momento, enquanto $10 \%$ optaram por manter uma opinião neutra sobre o tópico.

\footnotetext{
${ }^{4}$ iOS é um sistema operacional móvel da Apple Inc.
} 
Quanto à complexidade, todos os participantes concordaram que o aplicativo apresenta um nível de complexidade adequado ao público-alvo, tendo a maioria dos alunos conseguido executar as atividades propostas de maneira satisfatória e sem a necessidade de intervenção direta dos supervisores (pais e/ou responsáveis). A duração de cada fase dos jogos foi considerada "apropriada" por todos os participantes que estiveram supervisionando a realização dos testes. Os períodos de pausas entre as fases do jogo foram essenciais para que a criança pudesse descansar por alguns segundos e então voltar sua atenção às atividades novamente. Como consequência, os jogos foram bem-sucedidos em manter o interesse da criança durante todo o período de testes.

Em aspectos gerais, a totalidade dos participantes concordaram em afirmar que o aplicativo realiza de maneira satisfatória os objetivos a que se propõe, a saber, auxiliar no letramento básico, ensino dos numerais e reconhecimento de expressões faciais básicas ao interpretar emoções simples. Quanto a sua relevância, os participantes se mostraram favoráveis à utilização do aplicativo como ferramenta pedagógica no processo de ensinoaprendizagem de crianças portadoras de Deficiência Intelectual, uma vez que ela atua em auxílio ao desenvolvimento cognitivo das mesmas.

Como consequência da boa receptividade na realização dos testes, tanto por parte das crianças participantes quanto dos responsáveis e/ou profissionais educadores presentes, a totalidade dos entrevistados afirma que recomendaria o aplicativo ANE para utilização por outras pessoas. Quanto à experiência utilizando o aplicativo, 70\% dos participantes afirmaram que foi "Excelente", enquanto os demais (30\%) consideraram "Boa" a experiência. Quando questionados sobre quais funcionalidades gostariam de ver presentes nas próximas versões do aplicativo numa pergunta de múltipla escolha, a maioria dos participantes (80\%) marcou a opção "Mais fases nos jogos", constatando que o aplicativo possui demanda e potencial para expansão.

\section{Considerações finais}

A partir das considerações apresentadas neste trabalho, os recursos das tecnologias digitais de informação e comunicação são não apenas relevantes, mas necessários para se garantir um atendimento de qualidade aos indivíduos portadores de necessidades especiais, incluindo entre estes os portadores de Deficiência Intelectual, que embora tenham certas limitações decorrentes da deficiência, possuem potencial cognitivo e de aprendizado como qualquer outra criança. Os objetivos geral e específicos foram atingidos no decorrer do desenvolvimento dos jogos, uma vez que se mostraram úteis como ferramenta lúdica no processo de ensino-aprendizagem das letras (de "A" a “Z”), dos numerais (de " 1 " a "9') e na identificação de expressões faciais básicas (medo, tristeza, alegria, raiva), tendo sido testados e aprovados pelos usuários finais, conforme as observações dos profissionais e responsáveis envolvidos durante a realização dos testes.

Com base nos dados apresentados na penúltima seção deste trabalho, observa-se a necessidade de ajustes técnicos no aplicativo de jogos, como por exemplo: melhoria na qualidade dos efeitos sonoros, redução de comandos repetitivos, adição de funcionalidades como recursos de gravação ou captação de áudio para que ocorra a transição entre fases, mais 
fases nos jogos e recursos de animação. Verificou-se também a necessidade da inclusão de métricas para que seja possível acompanhar o desenvolvimento do aluno, como por exemplo através do armazenamento dos dados de acerto e erros do usuário e gráficos de desempenho. No intuito de expandir o público-alvo atendendo também a crianças com diferentes níveis de Deficiência Intelectual, propõe-se a customização do jogo incluindo diferentes níveis de dificuldade, conforme o grau de Deficiência Intelectual do usuário. Torna-se relevante a realização de um experimento com um grupo de crianças usuárias e outro grupo não usuário, para efeito de comparação e análise do desempenho de cada grupo e assim conseguir uma melhor avaliação dos resultados obtidos com a utilização do aplicativo.

A análise das respostas obtidas a partir do questionário de usabilidade pós-teste demonstra boa receptividade por parte dos usuários finais na utilização do jogos ANE como recurso educacional adicional, que embora não substitua as práticas pedagógicas tradicionais - nem sequer tem isso por objetivo -, serve de recurso educacional adicional capaz de captar a atenção do aluno portador de Deficiência Intelectual favorecendo o processo de inclusão da pessoa com deficiência ao se enquadrar como recurso de tecnologia assistiva. Como qualquer outro projeto acadêmico, o aplicativo inclusivo ANE precisará de ajustes contínuos, uma vez que é preciso acompanhar o avanço de novas tecnologias e recursos que se tornam disponíveis.

\section{Referências}

SILVA, Raquel C. \& MONTEIRO, Claudia F. Cromoterapia: um importante recurso terapêutico para a terapia ocupacional. Universidade do Vale do Paraíba -Univap, Faculdade de Ciências da Saúde - FCS, 2013.

MOREIRA, M. A. Teorias de Aprendizagem. São Paulo: Editora Pedagógica e Universitária, 1999.

MOURA, D. L. L., Filho, D. L. S. O., Silva, A. J. G., Paiva, P. V. V., Sales, T. B. $\quad$ M., Cavalcante, R. C., Queiroz, F. S. (2016). TEO: Uma suíte de jogos interativos para apoio ao tratamento de crianças com autismo. In Anais do XXVII Simpósio Brasileiro de Informática na Educação (SBIE 2016).

GOBBO, M., BARBOSA, C., MORANDINI, M., MAFORT, F. Aplicativo para Ganho de Vocabulário e Auxílio na Alfabetização destinado às Crianças com Transtorno do Espectro Autista. In Anais do VIII Congresso Brasileiro de Informática na Educação - CBIE 2019.

VASCONCELOS, M. M. Retardo mental. Jornal de pediatria, Porto Alegre, v. 80, n.2, p. S71-S82. Abr. 2004.

SIERRA. (2019). Construct2.

http://www.castanha.pa.gov.br/secretarias/\#Educacao, acesso em 05/03/19

BERSH, R. Introdução à Tecnologia Assistiva. 2017, Porto Alegre - RS, disponível em www.assistiva.com.br (acesso em 06/09/18)

TÉDDE, S. Crianças com Deficiência Intelectual: a aprendizagem e a inclusão. Americana: Centro universitário Salesiano de SP, 2012. Dissertação (Mestrado em Educação). UNISAL - SP.

https://play.google.com/store/apps/details?id=com.BrainyMouseFoundation.BrainyMouse $\&$ hl=pt, acesso em 04/03/2019 